\title{
Recurrent and Metastatic Papillary Thyroid Microcarcinoma Presenting as Toxic Multinodular Goiter
}

\author{
Shelton Tacang, MD ${ }^{1 *}$, Marcelino Tanquilut, $\mathrm{MD}^{2}$, Emelito O. Valdez-Tan, $\mathrm{MD}^{3}$, Wenceslao S. Llauderes, $\mathrm{MD}^{4}$ \\ ${ }^{1}$ Resident, Department of Nuclear Medicine, Jose R. Reyes Memorial Medical Center, Manila, Philippines \\ ${ }^{2}$ Chairman, Department of Nuclear Medicine, Jose R. Reyes Memorial Medical Center, Manila, Philippines \\ ${ }^{3}$ Vice-Chairman/Training Officer, Department of Nuclear Medicine, Jose R. Reyes Memorial Medical Center, Manila, Philippines \\ ${ }^{4}$ Active Consultant, Department of Nuclear Medicine, Jose R. Reyes Memorial Medical Center, Manila, Philippines
}

\begin{abstract}
Background: Hyperthyroidism does not safeguard individuals from developing thyroid cancer. Papillary thyroid microcarcinoma, notwithstanding its torpid course and low risk classification, has a propensity to induce significant morbidity despite radioactive iodine treatment. Clinical case: We present the unusual case of a 37-year old, Filipino male who demonstrated typical signs and symptoms of toxic multinodular goiter (TMG) including anterior neck mass, tremors, weight loss, excessive sweating, palpitations, easy fatigability and bilateral proptosis. The patient, upon follow up, was found to have agranulocytosis attributed to being on anti-thyroid medication for two years. The patient was then subjected to total thyroidectomy with a histopathology report showing colloid goiter with concomitant papillary thyroid microcarcinoma $(0.9 \mathrm{~cm}$ in widest diameter). Initial radioactive iodine (RAI) therapy was initiated following surgery and subsequent 131I whole body survey (WBS 131I) a year after, showing a negative result; however, after 2 months of WBS 131I, there was locoregional recurrence detected by neck ultrasound and CT scan, and eventually confirmed on lymph node biopsy after modified radical neck dissection (MRND). In an attempt to ablate the probable micrometastases, a second RAI therapy with a higher dose was administered; and subsequent post-therapy scan revealed recurrence of cancer on the thyroid bed and distant metastasis on the right lower quadrant of the abdomen. Currently, the patient is on suppression therapy and constantly monitored for progression of the disease. Conclusion: Even when aided with strict protocols, clinicians must recognize that guidelines are not surrogate to clinical judgment and that prompt institution of treatment is critical to circumvent potential pitfalls. This case further illustrates the avenue of championing the use of radioactive iodine (RAI) therapy just as in the low risk stratification.
\end{abstract}

Keywords: hyperthyroidism, papillary thyroid cancer, radioactive iodine therapy, toxic multinodular goiter
Vol No: 06, Issue: 02

Received Date: November 20, 2021

Published Date: December 30, 2021

\section{*Corresponding Author}

Shelton Tacang

Resident, Department of Nuclear Medicine, Jose R. Reyes Memorial Medical Center, Manila, Philippines.

E-mail: shelton1886@gmail.com

Citation: Tacang S, et al. (2021). Recurrent and Metastatic Papillary Thyroid Microcarcinoma Presenting as Toxic Multinodular Goiter. Mathews J Case Rep. 6(2):69.

Copyright: Tacang S. (C) (2021). This is an openaccess article distributed under the terms of the Creative Commons Attribution License, which permits unrestricted use, distribution, and reproduction in any medium, provided the original author and source are credited. 


\section{INTRODUCTION}

Thyroid cancer was, for decades, considered mutually incompatible with hyperthyroidism. For these conditions to occur at the same time was rare [1]. The assumption was that hyperthyroidism helped protect the thyroid from developing cancer [2]. Recent studies, however, reveal increasing association between the two. Incidence of toxic multinodular goiter (TMG), one of the most common causes of hyperthyroidism, harboring a malignancy is highly variable and reaches to 9.26 percent $[3,4]$. Furthermore, a literature review spanning 20 years of analysis show a 1.6 percent incidence rate of concurrent hyperthyroidism and thyroid cancer [5]. While incidental papillary thyroid microcarcinoma (PTMC) carries an excellent prognosis, it is not without complication. Albeit nodal and distant metastases are documented in reported series, the incidence rates are low.

This report presents a locoregional recurrence and distant metastasis from PTMC presenting as toxic multinodular goiter (TMG), which was presumed to be benign.

\section{CASE REPORT}

A 37-year old, Filipino male sought consult in a medical institution, in 2014, with a chief complaint of palpitations accompanied by tremors, weight loss, excessive sweating, palpitations, easy fatigability and proptosis (Fig. 1). Thyroid function tests revealed suppressed serum thyrotropin (TSH) of $<0.1 \mathrm{uIU} / \mathrm{mL}$ (reference value: $0.25-4.0 \mathrm{uIU} / \mathrm{mL}$, IRMA method) and elevated free $\mathrm{T} 4$ of $84 \mathrm{pg} / \mathrm{mL}$ (reference value: $7.0-18.0 \mathrm{pg} / \mathrm{mL}$, RIA method). Medications were administered - methimazole $20 \mathrm{mg}$ twice a day and propranolol $10 \mathrm{mg}$ thrice a day - with good compliance until the patient's condition improved. Upon follow up, thyroid ultrasound was instituted showing nodular colloid goiter on both lobes. Routine complete blood count, on the other hand, revealed presence of agranulocytosis that was attributed to anti-thyroid medication for the last two years. He was then advised to undergo total thyroidectomy in 2016. Histopathological report showed an incidental finding of papillary thyroid microcarcinoma (PTMC) with the malignant nodule on the left lobe measuring $0.9 \mathrm{~cm}(9$ $\mathrm{mm}$ ) in widest diameter and with colloid nodules on both lobes. The patient had no history of radiation exposure to the head and neck. Family history revealed that his mother had papillary thyroid cancer but did not undergo radioactive iodine therapy. Instead, she is on suppression therapy with levothyroxine.

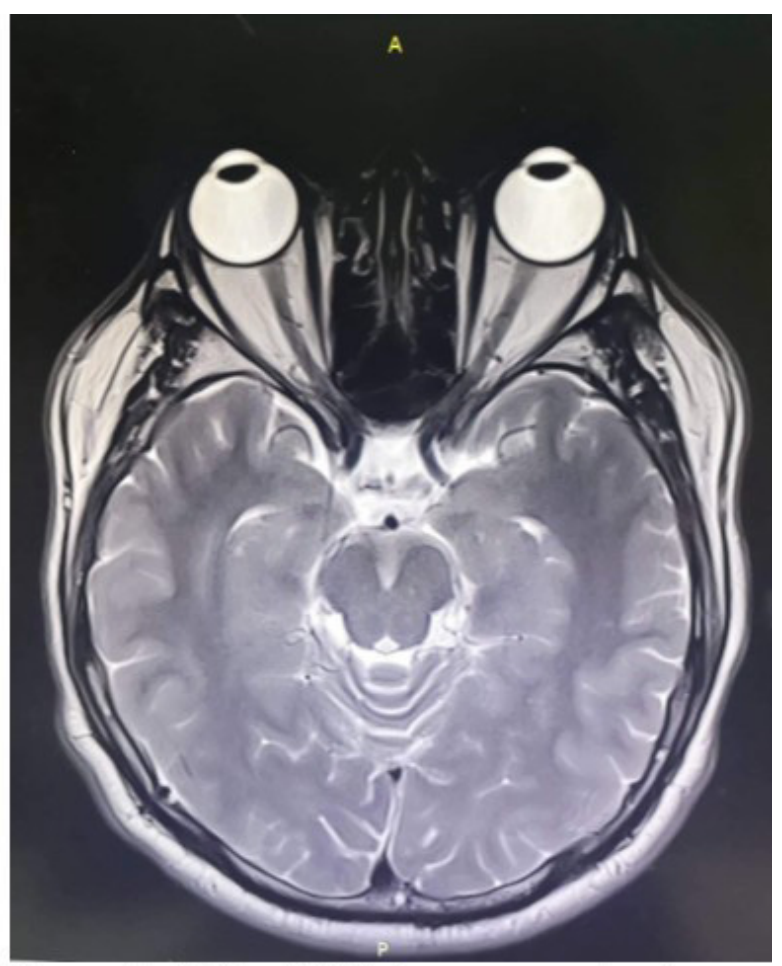

Figure 1: Orbital MRI shows excessive fat accumulation in bilateral retro-orbit with associated mild bilateral proptosis.

The patient was then referred to our department for radioactive iodine (RAI) therapy one month after surgery with negligible thyroglobulin level. The patient was given initially with $100 \mathrm{mCi}$ capsule of radioactive iodine. Wholebody I-131 survey (Fig. 2) showed negative result after 1 year of RAI therapy. Other tests included thyroglobulin of $7.44 \mathrm{ng} /$ $\mathrm{ml}$ (reference value: 2-70 $\mathrm{ng} / \mathrm{mL}$ ) and antithyroglobulin antibodies of $92.6 \mathrm{IU} / \mathrm{mL}$ (reference value: $<50 \mathrm{IU} / \mathrm{mL}$ ). Two months after the whole body I-131 survey, the patient palpated a small, fixed, nontender mass on the right lateral neck area. Ultrasound (image not shown) and plain CT scan of the neck (Fig. 3) were done showing a hypoechoic and enlarged lymph nodes, respectively. He was then scheduled for modified radical neck dissection (MRND) and the harvested lymph nodes were sent for biopsy. The lymph nodes of the lateral compartment (III, IV, and V, sparing II) of the neck were found to be metastatic in nature. Four weeks after the surgery, thyroid scan (Fig. 4) was done showing the absence of functioning thyroid tissue in the thyroid bed, followed by a second radioactive iodine therapy of $150 \mathrm{mCi}$ thereafter. Post RAI therapy scan (Fig. 5- 6) showed residual uptake on the thyroid bed and right lower quadrant of the abdomen denoting recurrence and distant metastasis, respectively. 


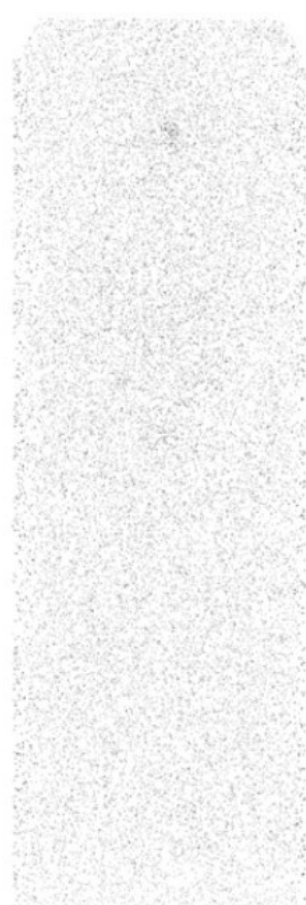

R ANTERIOR L

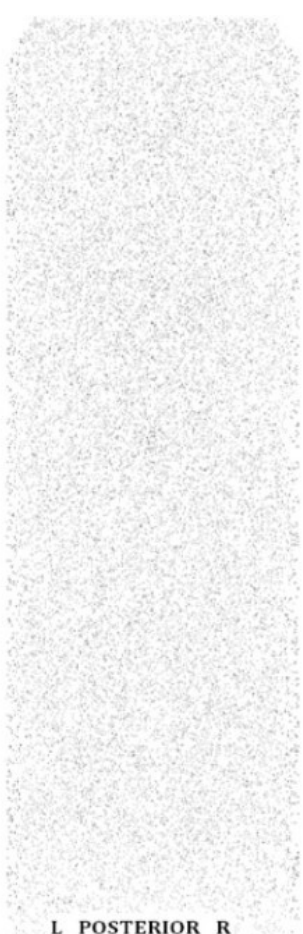

L POSTERIOR $\mathrm{R}$

Figure 2: Whole body survey I-131 shows no appreciable functioning thyroid tissue in the thyroid bed with no evidence of distant metastasis.

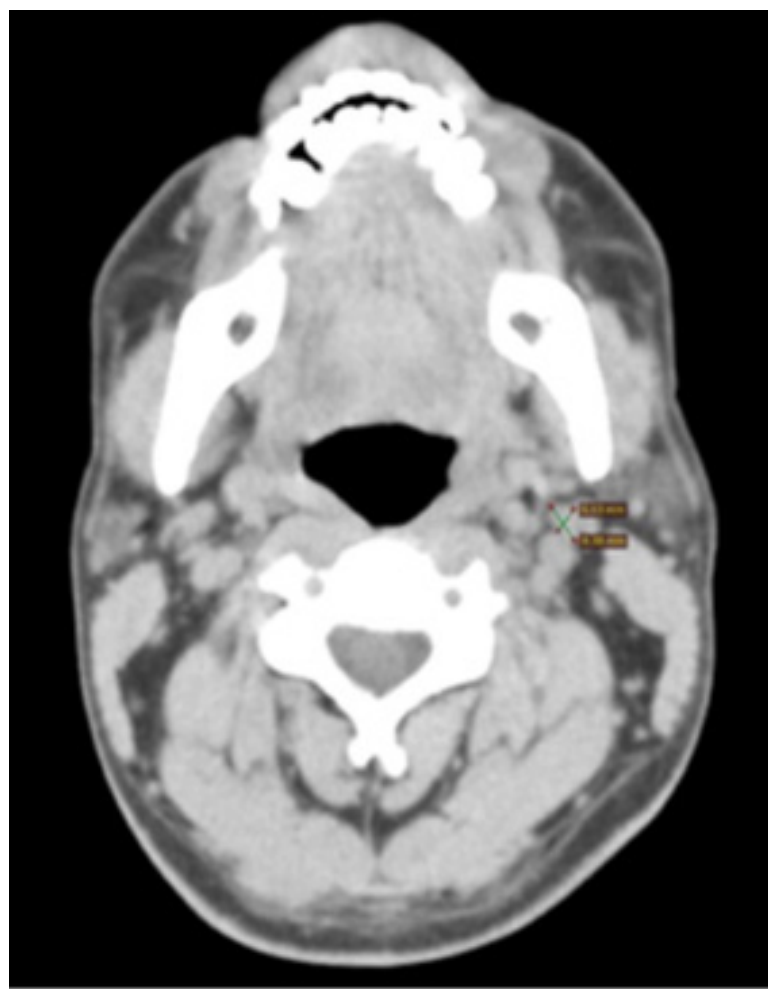

Figure 3: CT scan of the neck showing an enlarged lymph node

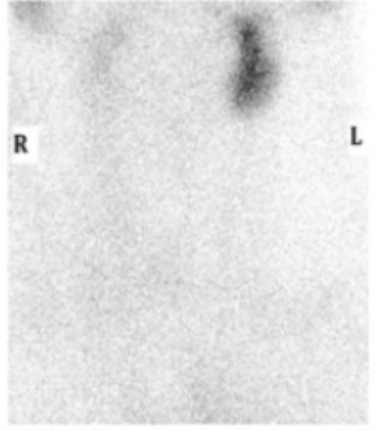

ANTERIOR
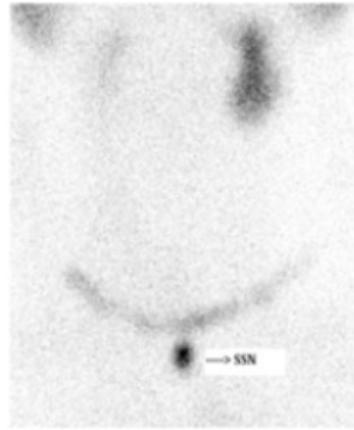

ANTERIOR WITH MARKER
Figure 4: Thyroid scan post right MRND using Tc-99m pertechnetate. Non-visualization of the thyroid in the thyroid bed with physiologic radiotracer uptake in the salivary glands.

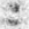

Figure 5: Post-therapy scan shows functioning thyroid tissues in the thyroid bed and right lower quadrant area

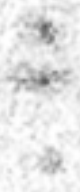

Figure 6: Spot view of the neck post therapy showing functioning thyroid tissue in the thyroid bed 


\section{DISCUSSION}

Carcinomas of the thyroid are still regarded as the most common malignancy of the endocrine system and take the ninth spot in the most common types of cancer overall [6]. Papillary thyroid cancer, a well-differentiated cancer, accounts for more than 85 percent of documented cases [7]. While majority of the patients are women, thyroid cancer in men ranges from 15.6 to 20 percent, in prevalence rate [811]. These cancers exhibit multifarious clinical presentations ranging from solitary to multinodular goiters with a typical presentation of being euthyroid [12,13,14]. Compelling scientific literatures, however, depict hyperthyroidism coexisting with thyroid cancer. Often, like this patient, incidental findings of concurrent hyperthyroidism and thyroid cancer can happen after surgery, which is intended as a means to achieve fast and permanent relief of symptoms of what was previously perceived to be benign disease $[14,15]$.

\section{Thyroid Cancer as an Incidental Finding}

Incidental thyroid cancers are not uncommon. Unlike this patient, incidental thyroid cancer is common among euthyroid individuals in 90.9 percent of the time [13]. Many of them had a preoperative diagnosis of benign thyroid disease. Papillary thyroid microcarcinoma, defined as neoplastic lesion of less than $1 \mathrm{~cm}$, is the most common incidental finding [15-17]. To ascertain the precise benignity of the thyroid nodules, fine needle aspiration (FNA) is initiated. Nonetheless, the benefit of FNA with lesions this small is limited [18]. Incidental and non-incidental PMTC alike report metastases to the lymph nodes in $0.65-5$ percent of the cases $[19,20]$ in which patients younger than 40 years old are documented to have a rapid clinical progression [21]. Thus, total thyroidectomy with or without radical neck dissection is a rational alternative.

\section{Hyperthyroidism and Cancer}

Hyperthyroidism, a common disorder, is a condition resulting from excessive levels of circulating thyroid hormones [11] from an overtly hyperfunctioning thyroid gland. The coexistence of hyperthyroidism and thyroid cancer was thought to be a rare condition, the former being viewed as protection from the development of the latter $[2,11]$. Toxic multinodular goiter (TMG), one of the most common causes of hyperthyroidism, has been documented to have unsuspected malignancy accounting to 7.14-9.26 percent in multiple surgical series $[4,15,16]$. This finding has been challenged by several authors in a separate series showing a hairline result of 1.62-1.65 percent of cases of malignancy in TMG [5,22]. Further, a more recent surgical commentary even reported that none of the cases of TMG (viz., 0 out of 26) was found to sustain malignancy [3]. Literatures of hyperthyroidism in thyroid cancer, on the other hand, are likewise inconsistent.

Experimental evidence shows a 1.65- 7.32 percent rate of associated malignancy $[3-5,15,23]$. This incongruity has instigated further investigations to substantiate the concurrent malignancy in hyperthyroidism and TMG, exhibiting an incidence rate of 5.6 percent and 5.9 percent, respectively, in a recent metaanalysis [24]. Albeit varied, the actuality of these findings is based on post-hoc analysis of all patients who underwent total thyroidectomy. That the mechanism of hyperthyroidism leads to the development of thyroid cancer is disconcerting. Several investigators could only theorize that faulty TSH receptor signaling pathway is the main culprit. Activating (gain-of-function) somatic mutations in the TSH receptor gene of aberrant follicular cells causes activation of intracellular cAMP from ATP by adenylyl cyclase [7]. This oncogene activation transmits specific, persistent signaling to produce hormones independent of TSH stimulation spawning a pathologic process of hyperthyroidism $[25,26]$. An annotation raises the possibility that premature stimulation of the thyroid gland by TSH may establish a fertile ground for tumor development even before the toxic state ensues [22]. These assessment findings, however, conjectural, have yet to be elucidated.

\section{Treatment}

\section{Radioactive Iodine}

The subsequent use radioactive iodine therapy after surgery for incidental and non-incidental PTMC is quite controversial. Various studies establish themselves a nonconcurrence of the use of radioactive iodine post operatively for these patients. Many guidelines do not recommend total thyroidectomy plus ablative therapy with I-131 following surgery in PTMC in the absence of multifocality and nodal metastasis but by lobectomy and observation alone [27]. In the same study, a 27.5 percent increase in tumor size, however, is exhibited by giving no treatment. A study by Chow et al, [28] resulted a zero recurrence in patients with lymph node negative who received radioactive iodine ablation. It went on to conclude that radioactive iodine ablation diminished the relative risk of lymph node recurrence and that a 20 percent reduction is seen in those patients with lymph node metastasis at presentation. Absence of radioactive iodine in positive lymph node metastasis at presentation has increased recurrence rate by 6.2- fold. Separate studies of PTMC patients who had near total or total thyroidectomy received a dosage of 30-200 mCi (average: $87 \mathrm{mCi}$ ) showed no evidence of recurrence $[4,10,11,18]$.

\section{Suppression Therapy}

The American Thyroid Association [21] (ATA) recommends, 
in the long term follow up, that differentiated thyroid cancer (DTC) be treated with L-T4 to reach the serum TSH level of $0.1 \mathrm{mU} / \mathrm{L}$ in patients with structural incomplete response to therapy. Meanwhile, serum TSH levels in patients with biochemical incomplete response, and excellent or indeterminate response to therapy be at 0.1-0.5 $\mathrm{mU} / \mathrm{L}$ and 0.5-2.0 mU/L, respectively. This recommendation holds true in the absence of specific contraindications.

\section{Recurrence and Distant Metastasis}

It has been established in many surgical series the excellent overall prognosis of PTMC, incidental or otherwise. Still, this does not exempt from carrying with it an eminent morbidity in a subset of patients. Studies have shown that a lymph node recurrence rate of 0.65-4.17 percent among incidental PTMC and 5 percent of the cases among non-incidental PTMC were observed with a mean follow up of 36 and 61 months, respectively $[19,20]$. Furthermore, a descriptive and metaanalysis study showed that distant metastases at diagnosis were seen among incidental and non-incidental groups in 1.24 percent and 3.18 percent, respectively [27]. Despite having an exceptional prognosis, recorded mortality in PMTC accounts to $0.34-1$ percent of the cases $[19,20,28,29]$. A more aggressive treatment at presentation accorded good outcomes, contributing to the high survival and low incidence of recurrence [23].

\section{CONCLUSION}

The prevalence of concurrent hyperthyroidism and thyroid cancer, although variable, is now being amplified. These entities were regarded as mutually exclusive, yet a number of alleged benign thyroid disease, after total thyroidectomy, turn out to be malignant. The rise in these incidental findings gives credence in the differences in the extent of thyroid resection and the number of histologic sections examined per specimen. Total thyroidectomy is the procedure of choice in dealing with TMG patients, not only to relieve their symptoms, but early detection of thyroid cancer and increase survival rates. Toxic multinodular goiter and hyperthyroidism alike do not exclude malignancy, and thyroid cancer may be considered in the differential diagnoses when confronted with either case. The cascade of events leading to the development of structural disease from a known low risk classification is a testament of how an indolent nature of a disease can transform into a significant clinical dilemma. This further translates the advent use of I-131 at any point in the risk stratification system.

\section{REFERENCES}

1. Hayes FJ, Sheahan K, Heffernan A, and McKenna TJ. (1996). Aggressive thyroid cancer associated with toxic nodular goiter. Euro J Endocrinol. 134:366-370.
2. Lin C, Chiang F, and Wang L. (2003). Prevalence of thyroid cancer in hyperthyroidism treated by surgery. Kaohsiung J Med Sci. 19(8):379-384

3. Askitis D, Efrenidou EI, Karanikas M, Mitrakas A, Pripsianis G, et al. (2013). Incidental thyroid carcinoma diagnosed after total thyroidectomy for benign thyroid disease: Incidence and association with thyroid disease and laboratory markers. Int J Endocrinol. 2013:451959

4. Ruggieri M, Scocchera M, Genderini M, Mascaro A, Luongo B, et al. (1999). Hyperthyroidism and concurrent thyroid carcinoma. Euro Rev Med Pharmacological Sci. 3(6):265-268.

5. Gabriele R, Letizia C, Broghese M, De Toma G, Celi $M$, et al. (2003). Thyroid cancer in patients with hyperthyroidism. Hormone Res. 60:79-83.

6. Nguyen QT, Lee EJ, Huang MG, Park YI, Khullar A, et al. (2015). Diagnosis and treatment of patients with thyroid cancer. American Health \& Drug Benefits. 8(1):30-40.

7. Kumar V, Abbas AK, Aster JC. (2013). Robbins basic pathology (9th Ed.). Philadelphia, PA: Elsevier

8. Maturo A, Tromba L, De Anna L, Carbotta G, Livadoti G, et al. (2017). Incidental thyroid carcinomas. A retrospective study. G Chir. 38(2):94-101.

9. Abdul Jabbar MQ, Mutlak NS, Abdul Hessein W, and Sulaiman TI. (2016). Incidental thyroid carcinoma, Fac Med Baghdad. 58(3).

10. Chao T, Lin J, Jeng L, and Chen M. (1999). Thyroid cancer with concurrent hyperthyroidism. Arch Surg. 134:130134.

11. Taneri F, Kurukahvecioglu O, Ege B, Yilmaz U, Tekin EH, Cifter C, et al. (2005). Clinical presentation and treatment of hyperthyroidism associated with thyroid cancer. Endocrine Regulations. 39:91-96.

12. Shaik IA, Muthukumarsamy G, Vidyadharan R, and Abraham SJ. (2007). High incidence of thyroid cancer in toxic multinodular goiters. Asia-Pacific J Clin Oncol. 3:119-124.

13. Dirikoc A, Faki S, Baser H, Ozdemir D, Aydin C, Ersoy R, et al. (2016). Thyroid malignancy risk in different clinical thyroid diseases. Turkish J Med Sci. 47:1509-1519.

14. Nanjappa N, Kumar A, Swain SK, Aroul TT, Smile SR, et al. (2013). Incidental thyroid carcinoma. Ind J Otolaryngol Head Neck Surg. 65(1):37-39.

15. Rios A, Rodriguez JM, Balsalobre MD, Torregrosa M, Tebar, FJ et al. (2005). Results of surgery for toxic multinodular goiter. Surg Today. 35:901-906. 
16. Cerci C, Cerci SS, Eroglu E, Dede M, Kapucuoglu N, et al. (2007). Thyroid cancer in toxic and non-toxic multinodular goiter. J Postgraduate Med. 53(3):157-160.

17. Smith JJ, Chen X, Schneider DF, Nookala R, Broome JT, et al. (2013). Toxic nodular goiter and cancer: a compelling case for thyroidectomy. Ann Surg Oncol. 20:1336-1340.

18. Pezzolla A, Marzaioli R, Lattarulo S, Docimo G, Conzo G, et al. (2014). Incidental carcinoma of the thyroid. Int J Surg. 12:S98-S102.

19. Roh J, Kim J, and Park CI. (2008). Central cervical nodal metastasis from papillary thyroid microcarcinoma: pattern and factors predictive of nodal metastases. Ann Surg Oncol. 15(9):2482-2486.

20. Wada N, Duh Q, Sugino K, Iwasaki H, Kameyama K, Mimura T, et al. (2003). Lymph node metastasis from 259 papillary thyroid microcarcinoma. Ann Surg. 237(3):399-407.

21. Haugen BR, Alexander EK, Bible KC, Doherty GM, Mandel S, et al. (2016). 2015 American thyroid association management guidelines for adult patients with thyroid nodules and differentiated thyroid cancer. Thyroid. 26(1):1-33.

22. Zanella E, Rulli F, Muzi M, Sianesi M, Danese D, et al. (1998). Prevalence of thyroid cancer in hyperthyroid patients treated by surgery. World J Surg. 22:473-478.

23. Vini L, Hyer S, Pratt B, \& Harmer C. (1999). Good prognosis in thyroid cancer found incidentally at surgery for thyrotoxicosis. J Clin Pathol. 75:169-170.
24. Negro R, Valcavi R, and Toulis KA. (2012). Incidental thyroid cancer in toxic and nontoxic goiter: Is TSH associated with malignancy rate? Results of metaanalysis. Endocr Pract. 19(2):212-218.

25. Kadia BM, Dimala CA, Bechem NN, and Aroke D. (2016). Concurrent hyperthyroidism and papillary thyroid cancer: a fortuitous and ambiguous case report from a resource-poor setting. BioMed Central Res Notes. 9:369.

26. Vudayaraju H, Korukonda S, and Dara H. (2016). Carcinoma thyroid with hyperthyroidism - a rare case report. Head Neck Cancer Res. 1:2.

27. Roti E, Uberti ECD, Bondanelli M, and Braverman L. (2008). Thyroid papillary microcarcinoma: a descriptive and meta-analysis study. Eur J Endocrinol. 159(6):659673.

28. Noguchi S, Yamashita $H$, Uchino $S$, and Watanabe S. (2008). Papillary microcarcinoma. World J Surg. 32(5):747-753.

29. Chow S, Law S, Chan JK, Au S, Yau S, et al. (2003). Papillary microcarcinoma of the thyroid-prognostic significance of lymph node metastasis and multifocality. Cancer. 98(1):31-40. 